\title{
Reparaciones: entre la derrota militar de Sendero Luminoso y la frustración democrática
}

Recibido: 12/09/2018

Aprobado: 04/1 1/2018

\author{
DEICI DÁVILA \\ Universidad Nacional Mayor de San Marcos \\ deicidavila@gmail.com \\ La lucha contra la violencia es la lucha \\ por el desarrollo con democracia \\ Efraín GonZales de Olarte
}

\section{RESUMEN}

El periodo de violencia política que envolvió al país entre 1980 y el 2000 dejó profundas heridas en miles de peruanos y puso al descubierto graves facturas sociales. La declaratoria de guerra por Sendero Luminoso movilizó las fuerzas del Estado, lo que provocó una violación de derechos humanos no solo entre ambos bandos, sino ante la población civil. La movilización social y la estrategia de inteligencia de la Policía puso fin a la violencia, pero solo el fujimorismo y las Fuerzas Armadas quisieron arroparse el triunfo. En el camino, cientos de miles de víctimas reclamaban justicia. Para lograr la reconciliación nacional, desde espacios como la CVR se recomendaron ante el Estado políticas de reparación a través de programas sociales. Sin embargo, una serie de factores vienen impidiendo que estas puedan ser efectivas.

Palabras clave: Democracia, subversión, Sendero Luminoso, Fuerzas Armadas, reparaciones.

\section{Reparations: between the military defeat of the Shining Path and democratic frustration}

\begin{abstract}
The period of political violence that engulfed the country between 1980 and 2000 left deep wounds in thousands of Peruvians and uncovered grave social debts. The war declared by The Shining Path mobilized State forces which caused severe violations of human rights, not only between both sides, but also within civilians. Social agitations and the strategy of police intelligence put an end to the violence, but the fujimorismo political sector and the armed forces attributed the victory to themselves. Meanwhile, hundreds of thousands of victims cried for justice. In order to achieve social reconciliation, institutions such as the Truth and Reconciliation Committee recommended that the State begin enacting reparations through social programs. However, a series of factors have prevented these from being effective.
\end{abstract}

Keywords: Democracy, subversion, The Shining Path, Armed Forces, reparations. 


\section{Presentación}

Tntre 1980 y el 2000, el Perú vivió el periodo de violencia más intenso y prolongado de su historia republicana, que ocasionó graves lesiones a la dignidad e integridad de miles de peruanos, y dejó al descubierto graves fracturas sociales. ${ }^{1}$ Este periodo de violencia tuvo su origen en la decisión de Sendero Luminoso de declararle la guerra al Estado peruano y destruir el desarrollo de la democracia que empezaba a gestarse con la Constitución de $1979 .{ }^{2}$

En los primeros años de la barbarie, el campesinado tuvo que adaptarse y resistir la presencia de Sendero Luminoso, que buscaba construir un nuevo poder en el campo a través de la ideologización maoísta y la imposición de autoridades. Sin embargo, a partir de 1982, los senderistas iniciaron una escalada de violencia contra la población a la que inicialmente decían proteger. Con el ingreso del Ejército para combatir la subversión en 1983, la guerra dio un giro dramático, viéndose la población civil en medio de "dos fuegos".

A partir de 1989, Sendero Luminoso incrementó la violencia contra el campesinado, logrando, contrariamente a lo imaginado, la multiplicación de rondas campesinas para la autodefensa. Ello coincidió con la nueva estrategia contrasubversiva de las Fuerzas Armadas y su acercamiento pragmático con las rondas campesinas para formar los comités de autodefensa (Degregori, 1996, p. 210). Con la conformación de las rondas inició el camino de resistencia del campesinado contra el senderismo, lo cual será un factor determinante para su derrota final con la captura de su máximo líder, Abimael Guzmán, camarada Gonzalo.

Con el golpe de Estado del 5 de abril de 1992 y la captura de Abimael Guzmán, el Gobierno de Fujimori usó este "triunfo" para perpetuarse en el poder. Se fue instalando la percepción de que el terrorismo podía revivir en cualquier momento y por eso era necesario el control total de las instituciones y de la vida pública por parte del Gobierno. El golpe legitimó también las medidas de ajuste económico que empobrecieron a millones de peruanos. Estas políticas de ajuste fueron claves para reasignarle al Estado un papel

1 Según la Comisión de la Verdad y Reconciliación, el periodo de violencia duró entre mayo de 1980 y noviembre del 2000.

2 El origen inmediato de la violencia fue la decisión política de Sendero Luminoso de declarar la guerra al Estado. El efecto devastador de los actos de violencia cometidos por Sendero tuvo, por su impacto nacional, una transcendencia mayor que los actos de barbarie cometidos por el Movimiento Revolucionario Túpac Amaru (MRTA). En este artículo nos centraremos en evaluar cómo se derrotó a Sendero Luminoso. 
cada vez más pequeño en la sociedad y situar al mercado como la nueva institución hegemónica.

Con la crisis y caída del régimen fujimorista, el Perú inició una nueva transición a la democracia. Como parte de este periodo, el gobierno de Paniagua creó la Comisión de la Verdad y Reconciliación (CVR) en el 2001. La creación de la CVR estuvo marcada por el proceso de institucionalización democrática, pero su importancia mayor radica en que brindó especial atención al testimonio de las víctimas, quienes entre las décadas de 1980 y 1990 fueron un factor de resistencia determinante para vencer a Sendero Luminoso. Sin embargo, su presencia fue ignorada por los gobiernos, y hoy sufren la revictimización a través de reparaciones que acabaron siendo políticas de lucha contra la pobreza.

Las reparaciones son un conjunto de acciones destinadas a reparar el daño causado por la violencia a las víctimas del periodo de 1980 al $2000 .{ }^{4}$ A través de las reparaciones, la democracia debería expresar el reconocimiento del Estado a quienes resistieron y combatieron la subversión, y fueron afectados gravemente en sus vidas, convirtiendo sus demandas en acciones concretas para enfrentar las consecuencias de la violencia, reconociendo su dignidad como ciudadanos y restableciendo su confianza en el Estado y la sociedad.

¿En qué se han convertido las reparaciones en el país? ¿Por qué se implementan a través de programas sociales? En este artículo se ensaya tres hipótesis para explicar qué factores contribuyeron a establecer las reparaciones a través de programas sociales.

En primer lugar, la derrota militar del senderismo ha sido interpretada como un triunfo del Ejército, soslayando el papel de la resistencia campesina para vencer a la subversión. Hacia fines de 1980, las rondas campesinas comenzaron a multiplicarse y resistieron la insania de Sendero Luminoso, lo cual coincidió con la implementación de una nueva estrategia de las Fuerzas Armadas. Sin embargo, lo "objetivo" fue el triunfo del Ejército, lo cual fue usado políticamente por Fujimori y legitimado en democracia. Siendo el reconocimiento a las víctimas un compromiso de la democracia, el discurso hegemónico de la victoria del Ejército termina debilitando las reparaciones al situar a las víctimas como parte del "costo social" de acabar con el terrorismo.

3 La CVR se crea a través del D.S. N. ${ }^{\circ}$ 065-2001-PCM. El Informe final de la CVR se publica en agosto del 2003. El Plan Integral de Reparaciones (PIR) figura entre sus recomendaciones más importantes.

4 Para ser beneficiarias de las reparaciones, las víctimas deben ser inscritas en el Registro Único de Víctimas del Consejo de Reparaciones, entidad adscrita al Ministerio de Justicia y Derechos Humanos. 
En segundo lugar, luego de la transición democrática del 2000, se siguió gobernando con las estructuras económicas y sociales heredadas del régimen fujimorista. Ello ha generado que se viva una especie de "frustración democrática", donde la mayoría de los derechos ciudadanos son reconocidos, pero en condiciones sociales limitadas para hacerlos efectivos. Ello se debería a que el Estado no ha logrado recuperar su rol hegemónico en la vida social. El mercado sigue teniendo un poder determinante en las decisiones del Estado, aliviando las demandas ciudadanas a través de programas sociales. Las reparaciones han seguido ese mismo camino. Pero las reparaciones no deberían ser programas de alivio a la pobreza, sino un conjunto de acciones donde el Estado exprese su reconocimiento a quienes resistieron y se enfrentaron a la subversión, y a quienes resultaron afectados en el desarrollo de sus vidas.

Por último, se ha soslayado el papel de la resistencia campesina y del pueblo para vencer a Sendero Luminoso. El campesinado sufrió el desprecio y la violencia del Estado y de Sendero, pero aun así combatieron por la pacificación. En la historia oficial, se ven solo "pobres víctimas", marginadas y excluidas, no actores de resistencia para la pacificación del país. Esta falta de reconocimiento ha conllevado a situaciones extremas donde los campesinos, víctimas y afectados por la violencia son tildados de "terroristas". Este aspecto sería un factor que explica por qué el Estado, en lugar de reparaciones, ha promovido "ayuda social" como medida de reparación.

\section{La "guerra" en democracia}

Las elecciones generales de 1980 fueron las más democráticas de nuestra historia republicana y coindicen con la aparición de la violencia política liderada por Sendero Luminoso, una agrupación pequeña que se había escindido de la izquierda peruana entre la década de 1960 y 1970.

Sendero Luminoso se caracterizó por su extremo fundamentalismo ideológico, así como su excesiva intolerancia para imponer sus ideas. La ideología senderista llevaba la violencia más allá de la guerra popular en términos maoístas. La violencia senderista era purificadora, donde lo viejo (el mal) tenía que ser extirpado a sangre y fuego, y el celo ideológico de los militantes era alimentado de manera constante por la dirección y el líder máximo (Degregori, 1996, p. 198). Como señala Tapia (1997, p. 14), “más que un partido el senderismo fue una ideología, convertida por voluntad de su líder 
máximo (Abimael Guzmán), en una férrea organización para la destrucción y la muerte".

En un inicio, Sendero Luminoso "ofrecía un orden autoritario y encaraba militarmente problemas concretos de campesinos empobrecidos" (Degregori, 2010, p. 54), siendo capaz de explotar el resentimiento contra el Estado de miles de ellos, quienes vivían en las zonas más alejadas del país. El factor clave de la expansión vertiginosa del senderismo entre 1980 y 1982 fue el engrosamiento de sus filas partidarias con un número significativo de jóvenes rurales con educación secundaria o incluso primaria. Para los jóvenes rurales, el partido significó una vía de movilidad social asociada al ejercicio concreto del poder en sus propias localidades (Degregori, 1996, p. 194).

Con la acción simbólica de la quema pública de las ánforas electorales en el distrito de Chuschi (Cangallo-Ayacucho) el 17 de mayo de 1980, Sendero Luminoso expresó su descreimiento en la democracia, el diálogo y el respeto por el "otro". Sendero se declaró enemigo del "viejo sistema", incluyendo a los partidos de izquierda, el APRA y las organizaciones populares, buscando evitar que estas siguieran "cabalgando sobre las masas" (Tapia, 1997, p. 16). Así como despreciaba a la democracia, Sendero despreciaba a los campesinos a quienes decía proteger. Para Sendero Luminoso, los campesinos eran "actores pasivos, ceros que solo adquirían valor al ser sumados a uno u otro bando", mientras el partido era el "depositario de la verdad", con un líder que era capaz de interpretar las "leyes de la historia" (Degregori, 1996, p. 215).

Los primeros ataques senderistas tomaron desprevenidos y carentes de un análisis certero al Estado. Una declaración del general Luis Cisneros Vizquerra, ministro de Guerra en 1982, describe claramente el escenario de la guerra a inicios de la década de 1980: "Yo establecería el toque de queda en Ayacucho y al que se mueva por la noche me lo tiro. ¿Qué otra medida represiva se puede tomar si no sabemos quiénes son?" (Gonzales, 1993, p. 9). En este escenario, la Policía ingresa al combate de la subversión "con un solo helicóptero y sin radios ni camionetas suficientes debían enfrentar a un enemigo sin rostro, ni uniforme, escondido entre la población civil" (Ejército del Perú, 2010, p. 30).

Mientras Sendero Luminoso se expandía en el campo, la lucha antisubversiva dio un giro dramático el 29 de diciembre de 1982, cuando el Gobierno de Belaunde le encarga a las Fuerzas Armadas el control del orden interno de las provincias de Huanta, La Mar, Cangallo, Víctor Fajardo y Huamanga en el departamento de Ayacucho; la provincia de Andahuaylas en el departamento de 
Apurímac; y la provincia de Angaraes en el departamento de Huancavelica. ${ }^{5}$ La militarización del conflicto ocasionó la renuncia del Gobierno civil como articulador de la lucha antisubversiva y la pacificación.

A fines de 1982, el escenario de la guerra estalló. Las Fuerzas Armadas tuvieron una feroz ofensiva militar en las zonas de emergencia entre 1983 y 1984, con el fin de "secar el agua al pez senderista" aterrorizando al campesinado para evitar su apoyo a Sendero Luminoso. Según Lewis Taylor, en esa época, "[...] los militares eran vistos por muchos campesinos como un ejército invasor, mientras que a Sendero Luminoso se le consideraba del 'equipo local', tal como se observó en la gran concurrencia al funeral de Edith Lagos. Diversos comentaristas señalaron que gran parte de la población serrana 'temía' a la guerrilla de Sendero, pero 'odiaba' a los soldados, una sutil distinción con importantes ramificaciones políticas y militares [...]” (en Ejército del Perú, 2010, p. 62).

Como se muestra en la siguiente tabla, 1984 pasará a la historia como el año más sangriento del periodo de la guerra antisubversiva. La violencia desatada entre Sendero Luminoso y el Ejército ocasionó el mayor número de muertos y desaparecidos entre 1983 y 1984.

Tabla 1

Muertes ocasionadas Por la Violencia durante El Gobierno de Belaunde (1980-1985), CLASIFICADO POR TIPO DE VÍCTIMA

\begin{tabular}{lccrrrr}
\hline \multicolumn{1}{c}{ Víctimas } & $\mathbf{1 9 8 0}$ & $\mathbf{1 9 8 1}$ & $\mathbf{1 9 8 2}$ & $\mathbf{1 9 8 3}$ & $\mathbf{1 9 8 4}$ & $\begin{array}{c}\mathbf{1 9 8 5} \\
\text { (julio) }\end{array}$ \\
\hline Fuerzas de seguridad & 1 & 2 & 39 & 92 & 99 & 65 \\
Civiles & 2 & 2 & 87 & 749 & 1758 & 410 \\
Presuntos subversivos & 0 & 0 & 44 & 1966 & 2462 & 884 \\
T otal & 3 & 4 & 170 & 2807 & 4319 & 1359 \\
\hline
\end{tabular}

Fuente: Burt (2011, p. 111).

El Gobierno de Belaunde es responsable del derramamiento de sangre producido entre el campesinado entre 1983 y 1984, pues dispuso el ingreso de los militares en la lucha antisubversiva sin tomar las previsiones necesarias para proteger a las poblaciones campesinas. La fallida estrategia militar de "secar el agua al pez senderista" habría sido diseñada "sobre la marcha" y acompañada de una "mala lectura" del fenómeno senderista (Ejército del Perú, 2010,

5 El 29 de diciembre de 1982 se publica en el diario oficial El Peruano el Decreto Supremo N. ${ }^{\circ} 068-82-\mathrm{IN}$. 
p. 30). De esta forma, el régimen democrático se vería gravemente afectado por las consecuencias inmediatas de la guerra: la expansión del conflicto a nivel nacional y el aumento exponencial de víctimas fatales.

Los partidos políticos de oposición — principalmente el APRA — formularon severas críticas a la conducción del conflicto. Se insistía en la necesidad de una reforma social para acabar con la "guerra sucia" ocasionada por el Ejército. ${ }^{6}$ Sin embargo, para los militares, el Gobierno les señalaba "qué no deberían hacer, sin recibir las directivas que orientaran su accionar" (Tapia, 1997, p. 39). De esta manera, las Fuerzas Armadas se desplegaron en un territorio desconocido en el que reprimieron indiscriminadamente, pues cualquiera era un enemigo potencial (Degregori, 1996, p. 210).

En el seno de la resistencia de las comunidades campesinas pronto afloraron diferencias con Sendero Luminoso. Los senderistas estaban dispuestos a matar y morir por el partido. En las comunidades, era común "castigar para corregir", pero no asesinar. El partido empezó a matar con crueldad, insania y desprecio por la vida, con lo cual "desgarra un tejido social muy delicado y abre una caja de Pandora que no es capaz de controlar" (Degregori, 1996, p. 201). En medio de la ofensiva militar, Sendero ordenó el repliegue de sus huestes para protegerlas, dejando desamparado al pueblo, lo que generó gran decepción entre los campesinos (Degregori, 1996, p. 205).

Mientras tanto, en Lima, motines senderistas en los penales de Lurigancho, El Frontón y Santa Bárbara fueron develados a sangre y fuego el 18 de junio de agosto de 1986, lo que produjo la muerte de cientos de internos. Este hecho fue duramente criticado por los partidos de oposición y las ONG de derechos humanos. Sin triunfos visibles por parte del Gobierno, la exigencia de respetar los "derechos humanos" aparecería como externa y "desleal", realizada por personas que no comprendían el escenario de la lucha contrasubversiva, y lo vivido por los campesinos a miles de kilómetros de la ciudad capital (Degregori y Rivera Paz, 1993, p. 12).

En 1987, la crisis económica originada tras la estatización de la banca afectó gravemente a todos los sectores sociales, incluyendo el militar. Los sueldos de quienes enfrentaban la subversión se volvieron magros y agudizaron la escasez de repuestos, municiones y pertrechos. Más grave todavía fue el reciclaje de los ranchos militares convertidos en platos para la indigencia. Consecuencia de ello, los patrullajes se redujeron en un $70 \%$, se suspendieron

6 Mensaje del presidente constitucional del Perú, Alan García Pérez, ante el Congreso Nacional, el 28 de julio de 1985 . 
la mayoría de vuelos en helicóptero y se cancelaron las operaciones de inteligencia (Ejército del Perú, 2010, p. 179).

El año 1989 será recordado como el que mayor mortandad de autoridades y representantes electos a nivel nacional tuvo. Ese año la "vacancia municipal" por abandono de cargo se extendió en los departamentos afectados por la subversión como Junín, Lima, Ayacucho, Huánuco, Apurímac, Áncash, Huancavelica, Pasco, La Libertad, Puno y San Martín. El repliegue de la autoridad democráticamente elegida será un duro golpe para el régimen que no encontraba las herramientas democráticas para vencer al terrorismo.

El número de víctimas fatales se incrementó nuevamente a mediados de 1989 cuando Sendero Luminoso buscó alcanzar el "equilibrio estratégico" a través del reclutamiento de cuadros jóvenes y el aumento de demandas al campesinado, bajo la amenaza de pena de muerte a los "traidores". De 697 fallecidos en 1987 se pasó a 3049 fallecidos en 1989, es decir, en dos años se quintuplicó el número de víctimas como se puede apreciar en el siguiente cuadro.

\section{Tabla 2}

Muertes oCASIONADAS POR LA VIOLENCIA DURANTE El Gobierno de GarCía (1986-1990) CLASIFICADO POR TIPO DE VÍCTIMA

\begin{tabular}{lccccc}
\hline \multicolumn{1}{c}{ Víctimas } & $\mathbf{1 9 8 6}$ & $\mathbf{1 9 8 7}$ & $\mathbf{1 9 8 8}$ & $\mathbf{1 9 8 9}$ & $\begin{array}{c}\mathbf{1 9 9 0} \\
\text { (julio) }\end{array}$ \\
\hline Fuerzas de seguridad & 135 & 126 & 289 & 348 & 258 \\
Civiles & 510 & 388 & 1030 & 1450 & 1584 \\
Presuntos subversivos & 622 & 183 & 667 & 1251 & 1542 \\
Total & 1268 & 697 & 1986 & 3049 & 3348 \\
\hline
\end{tabular}

Fuente: Burt (2011, p. 122).

En medio de la ofensiva senderista, el campesinado optó por organizar rondas y comités de defensa civil para combatir la subversión. ${ }^{7}$ Dos factores contribuyeron a la generalización de las rondas campesinas y su resistencia en el campo: el incremento de demandas de Sendero Luminoso sobre el campesinado, provocando el incremento de sus resistencias; y un cambio en la estra-

$7 \quad$ A fines de 1991, Ayacucho llegó a contar con aproximadamente 836 comunidades organizadas en comités de autodefensa. De ellas, 280 correspondían al valle del río Apurímac y tenían bajo su control el 95\% del valle. Y en 1994, el Comando Conjunto de las Fuerzas Armadas registraba para Ayacucho 1564 comités de autodefensa, con 61450 ronderos organizados y 5583 armas distribuidas, de un total nacional de 4205 comités, 235465 integrantes y 16196 armas (Degregori, 1996, p. 26). 
tegia de las Fuerzas Armadas, que pasaron de la represión indiscriminada a una represión más selectiva y a relaciones paternalistas con los campesinos.

La nueva relación entre las rondas campesinas y las Fuerzas Armadas fue pragmática. A diferencia de Sendero Luminoso, las Fuerzas Armadas no pretendieron controlar "todo sin excepción". Es interesante observar cómo la generalización de las rondas y su nueva relación con las Fuerzas Armadas no fue considerada como "una derrota importante" por la cúpula senderista. Esta desorientación del "pensamiento Gonzalo" respondería, entre otros aspectos, a su culto desmedido a la violencia, el "fatalismo optimista" de su concepción teleológica de la historia y su desprecio por la cultura andina (Degregori, 1996, pp. 211-214).

En un contexto de pasividad e inoperancia de los gobiernos civiles y partidos políticos para enfrentar la subversión, fue madurando la nueva estrategia contrasubversiva de las Fuerzas Armadas. A mediados de agosto de 1989, el Ejército aprobó el manual Guerra no convencional. Contrasubversión, ${ }^{8}$ donde "se caracterizó adecuadamente a las organizaciones a las que se combatía, analizó sus estrategias y describió con precisión su modo táctico de operar, señalando sus deficiencias y flancos débiles" (Tapia, 2018, p. 63). En el manual se precisó que el combate a la subversión requería de estrategias de inteligencia en un $80 \%$ y de operaciones militares en un $20 \%$, enfatizando que lo que estaba en disputa en el conflicto era el apoyo de la población.

En el campo, los campesinos ya se habían organizado en rondas y comités de defensa civil. Sobre estas organizaciones comunales, el Ejército promovió la formación de los comités de autodefensa (CAD) en Ayacucho y en todos los comités regionales donde Sendero Luminoso mostraba más actividad. ${ }^{9}$ Asimismo, se potenció la Dirección contra el Terrorismo (DIRCOTE) de la Policía Nacional, conformándose un grupo de operaciones encubiertas que derivó en el Grupo Especial de Inteligencia (GEIN).

En 1989, la guerra había ocasionado el 63.6\% del total de muertos y desaparecidos reportados a la CVR. A contracorriente de las promesas de "reforma social", el Gobierno de Alan García optó por militarizar la lucha contrasubversiva sin tener un mayor conocimiento del enemigo que se combatía, por ello, tiene responsabilidad en la extensión de la violencia en tiempo y espacio.

8 Manual ME 41-7, aprobado el 9 de agosto de 1989 por el comandante general del Ejército.

9 Los comités de autodefensa fueron instruidos en tácticas militares y se les implementó con escopetas. Hacia 1990, en el departamento de Ayacucho funcionaban 300 comités de autodefensa, en Apurímac 200, en Junín 350, en Huancavelica 150 y en Pasco 20 (Tapia, 2018, p. 72). 
En tanto, la resistencia campesina hacía retroceder a las huestes senderistas hacia Lima ("huida hacia adelante") y el Ejército alistaba una nueva estrategia contrasubversiva. En este escenario, el gobierno civil quedaba relegado como actor importante en la derrota final de Sendero Luminoso y la pacificación.

\section{Fujimori y la derrota militar de la subversión}

Para inicios de 1990, sesenta y cinco provincias del país se encontraban en estado de emergencia. En este escenario, las principales demandas de la opinión pública se centraban en la necesidad de derrotar la subversión y enfrentar la crisis económica heredada del Gobierno de García. El triunfo de Alberto Fujimori y su partido político Cambio 90 en las elecciones de 1990 —un líder desconocido y una organización "nueva" en política - mostrarían las señales más visibles de la crisis de los partidos y el avance de los llamados outsiders en la política nacional (Adrianzén, 2009, p. 88).

A contracorriente de sus promesas electorales, el Gobierno de Fujimori aplicó un severo ajuste económico que impuso altos costos sociales y sumió en la pobreza a millones de peruanos. "Al ponerse en práctica el programa de shock de Fujimori, el número de peruanos en situación de pobreza casi se duplicó, de 6 a 11 millones, la mitad de la población del país” (Burt, 2011, p. 81). Sin embargo, en respuesta al shock, hubo escasas protestas. Eso se debería, a decir de Burt (2011, p. 83), a "una extraña mezcla de temor y desesperación, así como de esperanza en que algo bueno pudiera resultar de este terrible sacrificio, [que] dominó la escena".

Fujimori llegó al Gobierno sin tener una propuesta específica sobre la pacificación del país. Ante ello asumió los riesgos y costos que implicaba poner la pacificación como el principal punto de agenda. Lo grave es que, ante la ausencia de una alternativa propia, su Gobierno asumió una estrategia que dio a las Fuerzas Armadas un papel político sobredimensionado en la vida pública (Tapia, 2018, p. 77).

En junio de 1991, el Congreso delegó al poder Ejecutivo la facultad de legislar sobre la pacificación a través de decretos legislativos. Con el pretexto de que el Congreso no quería aprobar este nuevo marco legal, la noche del 5 de abril 1992 Fujimori disolvió el Congreso, iniciando un "Gobierno de Emergencia y Reconstrucción Nacional”. Tras el golpe, las Fuerzas Armadas ingresaron a las universidades de San Marcos, Ingeniería y La Cantuta. 
Asimismo, se intervinieron los penales. Con estos hechos, el Gobierno quería demostrar la voluntad para combatir el terrorismo. El amplio apoyo popular al cierre del Congreso y demás medidas aparecieron como "el colofón a una historia de doce años de defección de gobiernos civiles y partidos políticos en el planteamiento de una estrategia democrática de pacificación" (Degregori y Rivera Paz, 1993, p. 17).

El 12 de setiembre de 1992, el GEIN capturó a Abimael Guzmán, lo cual significó el inicio del descalabro de Sendero Luminoso, sobre todo porque "cuajó en el país la idea-fuerza de que el terrorismo estaba siendo derrotado" (Tapia, 2018, p. 92). Hábilmente, el régimen de Fujimori afirmó que el golpe de Estado había posibilitado el arresto de Guzmán, argumento que les permitió institucionalizar las reformas de ajuste económico con relativa facilidad y crear un capital político importante para el régimen.

Como consecuencia de la captura de Guzmán, miles de militantes de Sendero Luminoso decidieron colaborar con la justicia a través de la Ley de Arrepentimiento promulgada en mayo de 1992. Esta norma, que no fue propuesta por ningún Gobierno en la década de 1980, permitió desarticular con cierta facilidad la agrupación terrorista a cambio del reducimiento de penas. A ello se sumó el pedido del "presidente Gonzalo" para llegar a un "acuerdo de paz" con el Gobierno, el cual se firmó en julio de 1993, luego de que Guzmán lograra mejoras carcelarias. ${ }^{10}$

Sendero Luminoso fue derrotado militarmente. En esta derrota tuvo un rol fundamental la resistencia campesina y organizada de las comunidades. A fines de la década de 1980, las rondas campesinas y los comités de defensa civil comenzaron a multiplicarse entre Ayacucho y Apurímac debido al crecimiento de las demandas senderistas sobre el campesinado: exigencia de un mayor número de jóvenes, entrega de más víveres, mayor participación de la población en acciones militares, entre otros. Todo ello ocasionó un profundo rechazo del campesinado (Degregori, 1996, p. 210).

Si bien las rondas campesinas estaban supeditadas al Ejército, su situación era más compleja y ambigua. Como señala Degregori, los ronderos estaban orgullosos de haber ganado la guerra, incluso de ser mejores combatientes que los militares. Este orgullo, sin embargo, era prudente, reclamando la pre-

10 "Ahora pienso que él estaba más ansioso que nosotros por firmar el Acuerdo de Paz. Si las conversaciones se alargaron fue porque quería mejoras carcelarias. Le permitieron llamar a sus suegros, pasear en una embarcación, reunirse con Elena Iparraguirre una vez por semana, recibir libros y publicaciones, etc. Apenas las alcanzó, estampó su firma. Era, es un hombre sumamente débil". Rafael Merino sobre el Acuerdo de Paz firmado por Abimael Guzmán en 1993 (Tapia, 2018, p. 96). 
sencia del Estado para la reconstrucción de sus comunidades y reclamando la protección militar como una suerte de última línea de defensa (Degregori, 1996, p. 26). Por ello, la derrota de Sendero Luminoso interpretada solamente como triunfo del Ejército es inexacta y ha soslayado el papel de la resistencia campesina para vencer a la subversión.

A pesar del declive de las acciones subversivas, el número de zonas de emergencia no disminuyó. El régimen de Fujimori mantuvo un esquema de “contrasubversión sin subversión”, lo cual significó el repliegue por muchos años del poder político civil en varias regiones del país y la militarización de la vida pública, sembrando la desconfianza en la democracia y sus procedimientos.

La "cultura del miedo" fue uno de los instrumentos más usados por el régimen de Fujimori para controlar a la sociedad. El miedo impactó en la vida de miles de peruanos, quienes estuvieron dispuestos a renunciar a sus derechos a cambio de las promesas de orden y seguridad. Para ello, el régimen usó operaciones psicosociales dirigidas por el Servicio de Inteligencia Nacional (SIN) y realizadas gracias al creciente control de los medios de comunicación ("diarios chicha" y los canales de televisión de señal abierta). En los medios se explotaba la presencia del "terrorismo" y las acusaciones de "ser terrorista", azuzando los miedos de la población. ${ }^{11}$

Durante la década de 1990, el Estado fue perdiendo peso político frente al mercado. El repliegue del Estado socavó la capacidad de los ciudadanos, sobre todo de los más pobres, para negociar la crisis, lo que condujo a una pérdida dramática de confianza en el Estado. En este contexto de descomposición institucional, la ciudadanía y el Estado de derecho fueron dejados de lado, lo que socavó aún más el débil ejercicio de la ciudadanía en el Perú (Burt, 2011, pp. 102-103). De esta forma, se facilitó la formación de una opinión pública pragmática que se inclinaría a apoyar a Fujimori por casi una década (Adrianzén, 2009, p. 140-147).

El régimen autoritario de Fujimori se diluyó en sus propias contradicciones y debilidades. El 19 de noviembre del 2000, Fujimori renunció a la Presidencia de la República vía fax, luego de huir al Japón tras el escándalo de la difusión de los "vladivideos". En medio de la condena nacional, los vicepresidentes fueron obligados a renunciar para dar paso al Gobierno de

11 Recordemos cómo, con la finalidad de legitimar su irregular re-reelección, Fujimori no dudó en montar desde el SIN un gran operativo destinado a hacer fracasar la Marcha de los Cuatro Suyos y estigmatizar a sus organizadores como terroristas. 
transición de Valentín Paniagua, quien en ese momento se desempeñaba como presidente del Congreso. El cambio de régimen, como veremos, no significó un cambio en el orden político, social y económico implantado con el autogolpe del 5 de abril de 1992.

\section{Triunfo ético de la CVR}

Como parte del periodo de "instalación" de la democracia, el Gobierno de Paniagua creó la Comisión de la Verdad y Reconciliación (CVR) en el 2001, ${ }^{12}$ con el objetivo de investigar y analizar las condiciones políticas, sociales y culturales que contribuyeron al origen de la violencia entre mayo de $1980 \mathrm{y}$ noviembre del 2000. La CVR buscó esclarecer los crímenes y violaciones a los derechos humanos cometidos por las organizaciones subversivas y agentes del Estado, así como también recomendó un plan de reparaciones para las víctimas y sus familiares.

La creación de la CVR estuvo marcada por la caída del régimen de Fujimori y la aspiración de tener un proceso de institucionalización democrática. Por ello, el Informe final de la CVR (IF-CVR) se convirtió en un llamado de atención a la opinión pública y a las élites políticas sobre su incapacidad para comprender las dimensiones de la violencia (Tanaka, 2013). El aporte principal del IF-CVR es que brindó especial atención al testimonio de las víctimas, lo que ha sido fundamental para su reconocimiento y la posterior implementación de las reparaciones.

El IF-CVR señaló que la causa inmediata del desencadenamiento de la violencia fue la decisión de Sendero Luminoso de iniciar la lucha armada contra el Estado peruano, en momentos en que se restauraba la democracia a través de elecciones. La población campesina y quechuahablante fue la principal víctima de este periodo, evidenciando un patrón de la violencia: "A mayor pobreza y exclusión social, mayor probabilidad de ser víctima del terrorismo", lo que pone en manifiesto las desigualdades de índole étnicas, culturales y socioeconómicas que aún prevalecen en el país.

El IF-CVR condenó el uso indiscriminado de la violencia por parte de las fuerzas del orden que produjo violaciones masivas de los derechos humanos. Empero la responsabilidad de quienes gobernaron el país durante las

12 La CVR se crea a través del D.S. N 065-2001-PCM). El Informe final de la CVR se publica en agosto del 2003. El Plan Integral de Reparaciones (PIR) figura entre sus recomendaciones más importantes. 
etapas más cruentas de la violencia no se ha establecido en su real dimensión. Durante el segundo Gobierno de Belaunde y el primer Gobierno de García ocurrieron el $64 \%$ de víctimas fatales del periodo de violencia. ¿Por qué el conflicto se prolongó desmesuradamente en tiempo y espacio?

Los expresidentes Belaunde, García y Fujimori “carecieron de la comprensión necesaria del conflicto". Peor aún, Belaunde y García cometieron faltas graves al dejar sin dirección política la lucha antisubversiva. En un escenario donde el enemigo era desconocido, resultaba fundamental el compromiso del Gobierno democrático en la construcción de una estrategia contrasubversiva en los primeros años de la barbarie. La extensión en tiempo y espacio de la violencia no solo generó pérdidas humanas y económicas, también arrinconó y debilitó la democracia como medio para pacificar y desarrollar al país. En el caso de Fujimori, la justicia se hizo cargo de sus faltas y delitos, al proteger a los agentes estatales que cometieron crímenes durante su régimen autoritario.

El impacto de la violencia mostrada en el IF-CVR determinó que el escenario de la guerra se dio en mayor tiempo y espacio fuera de Lima. El $85 \%$ de las víctimas se registraron en los departamentos de Ayacucho, Junín, Huánuco, Huancavelica, Apurímac y San Martín; el 79\% de las víctimas vivieron en zonas rurales y el $56 \%$ se ocupaba en actividades agropecuarias; asimismo, el $75 \%$ de las víctimas fatales tenían el quechua u otras lenguas nativas como idioma materno. Quizá, por eso, la violencia se dimensionó lejana para la mayoría de peruanos, quienes valoraron su solución a cualquier "costo", otorgando legitimidad al accionar militar contrasubversivo.

Para una parte de la opinión pública, la CVR habría sido "muy blando con Sendero Luminoso y muy duro con las Fuerzas Armadas", ${ }^{13}$ y el rol de las rondas campesinas en la pacificación es inexistente. Este encumbramiento del triunfo del Ejército sobre la subversión ha traído como consecuencia una falta de reconocimiento y solidaridad del resto de la sociedad con el "pueblo" (rondas, líderes comunales, víctimas, entre otros) que combatió la subversión. Hoy, las Fuerzas Armadas es una de las instituciones en las que más confían los peruanos, y se ha extendido la opinión favorable sobre su presencia para poner orden y seguridad en las calles. ${ }^{14}$

13 El 55\% de peruanos considera que Alberto Fujimori "fue un gobernante de mano dura, que acabó con el terrorismo y disminuyó los conflictos sociales". GFK, marzo del 2017. "Informe especial sobre el fujimorismo. Encuesta nacional urbano rural".

14 El Comercio, 1 de octubre del 2017: “Encuesta: ¿En qué instituciones confían los peruanos?”. 
El triunfo ético pero no político del IF-CVR es un factor importante para entender por qué las reparaciones se vienen implementando a través de programas sociales. Para la opinión pública, el IF-CVR no ha logrado reconciliar al país. ${ }^{15}$ Consecuencia de ello, sus recomendaciones se vienen implementando sin mayor compromiso político por los gobiernos de turno. Ello explica, también, por qué el fujimorismo, en alianza con sectores ultraconservadores, cuestiona el IF-CVR, buscando deslegitimar las reparaciones y a sus beneficiarios, tildándolos de "terroristas”. El IF-CVR polariza al país y a la opinión pública. De esta manera, los gobiernos no se atreven a legitimar la narración de la violencia y las recomendaciones de la CVR en su real dimensión.

\section{Frustración democrática}

Adrianzén (2009, pp. 168-169) afirma que el "cambio de régimen" ocurrido al final del Gobierno de Fujimori no se trató de una transición clásica de un Gobierno militar (autoritario) a uno civil (democrático). Se trató, por un lado, de una transición que se inicia con el colapso del régimen autoritario de Fujimori y, por el otro, de una transición por "negociación" en el Congreso.

El presidente Valentín Paniagua tuvo la oportunidad de elegir entre una "continuidad institucional" o procesar "una ruptura", lo que hubiera significado iniciar un proceso de reforma constitucional que abriera paso a un nuevo orden político, social y económico. Lynch $(2009$, p. 127) señala que la falta de ruptura constitucional permitirá a los gobiernos posteriores aferrarse, más allá de las promesas electorales, a la Constitución de 1993 y sus serias limitaciones para la democracia. En esa medida, Paniagua habría cumplido con el "acto fundacional" de transitar de la dictadura a la democracia en términos institucionales, pero quedaría pendiente la consolidación democrática que implica refundar el país a través de un nuevo contrato social.

El Gobierno de Alejandro Toledo se aferró a la estructura institucional heredada del fujimorismo. "Nunca llegaron a estar totalmente claras las intenciones de Toledo de establecer una ruptura con la dictadura de Fujimori y Montesinos" (Lynch, 2009, p. 128), incluso Toledo llegó a decir que Fujimori había construido el "primer piso" y que él construiría el segundo, haciendo alusión a las reformas neoliberales del Consenso de Washington. Al año y

15 GFK, marzo del 2017: "Informe especial sobre el fujimorismo. Encuesta nacional urbano rural". 
medio de Gobierno, las "mesas de diálogo" para resolver los conflictos fueron una constante, evidenciando la necesidad de más Estado para enfrentar las demandas sociales. Toledo no pudo enfrentarse a la ofensiva de los defensores del neoliberalismo, para quienes el colapso del Estado constituía un desarrollo positivo para el país y confirmaba la veracidad de los principios del libre mercado (Burt, 2011, p. 87).

El miedo a repetir el fracaso de su primer Gobierno alejaría a Alan García de cualquier tentación "progresista" y de cualquier compromiso con la transición democrática (Lynch, 2009, p. 133). Durante su segundo Gobierno, García se convirtió en el más radical guardián del régimen económico y político instaurado por Fujimori. Quizá la mayor muestra de su defensa del modelo sea el rol que jugó en el estallido del Baguazo, conflicto social que dejó treinta y tres muertos y un desaparecido. En un artículo publicado en El Comercio, García ofendió a las comunidades nativas y campesinas llamándolas "perros del hortelano", mostrando su absoluto apoyo a la propiedad privada por encima del diálogo y los derechos comunales.

El viraje político del presidente Ollanta Humala será el mayor golpe político recibido por la izquierda y el progresismo en la última década. Humala llegó al poder en el 2011 generando expectativas de inclusión y cambio social en el país. Sin embargo, dejó de lado sus promesas electorales y mantuvo las estructuras del régimen fujimorista, promoviendo programas asistenciales para los más pobres. Al finalizar su mandato, sus principales ofertas de campaña, como la seguridad ciudadana, la lucha contra la corrupción y la falta de oportunidades económicas seguían siendo demandas insatisfechas.

El desprestigio de la clase política vive un nuevo capítulo con los escándalos de corrupción que vinculan a los expresidentes Alejandro Toledo, Alan García, Ollanta Humala y Pedro Pablo Kuczynski por, supuestamente, haber recibido sobornos de la constructora brasileña Odebrecht para facilitar proyectos de inversión durante sus gobiernos. Esta crisis es apenas la punta del iceberg de la falta de compromiso de las élites políticas por construir una nueva representación, lo que se traduce en el avance de los poderes fácticos como garantes de la gobernabilidad del país.

En el 2017, solo el 16\% de peruanos señaló estar "satisfecho" con el "funcionamiento de la democracia", mientras que el 80\% consideró que se gobierna "para favorecer a grupos poderosos". Asimismo, el 70\% de peruanos dijo sentir "mucha desconfianza" respecto a la labor que realizan las ins- 
tituciones encargadas de impartir justicia y legislar. ${ }^{16}$ Por otro lado, según el INEI, la tasa de pobreza monetaria aumentó por primera vez en el milenio en el 2017, ${ }^{17}$ echando abajo el discurso del Perú como país cercano al "primer mundo". Así, por ejemplo, si en el 2004 un poblador rural tenía el doble de probabilidades de ser pobre que un poblador urbano, al 2014 dicha probabilidad se ha triplicado. ${ }^{18}$

Toledo, García, Ollanta y Kuczynski mantuvieron el "piloto automático" del modelo económico generado tras el periodo de ajuste económico de la década de 1990, el cual se sostiene en el sector extractivo de materias primas y fomenta una economía laboral informal. El 70\% de la PEA nacional, es decir, catorce millones de peruanos, trabajan fuera de las planillas, con horarios por encima de las ocho horas laborales y "recurseándose" para poder cumplir con las demandas familiares. ¿Qué peruanos puede sentirse satisfecho con un régimen "democrático" en el que tiene que sobrevivir?

Para Lynch (2009), el principal problema de la democracia sería la convivencia entre una democracia política en la que, cada cierto tiempo, ejercemos nuestros derechos civiles y políticos, en medio de demandas sociales y económicas insatisfechas. Las políticas de liberalización del mercado no mejoraron la calidad de vida de la mayoría de ciudadanos como fue su promesa. En este escenario se ha consolidado un régimen democrático político-electoral, dejando a la "mano invisible" del mercado la tarea de establecer las condiciones sociales y económicas en favor de unos y en detrimento de otros. En este panorama, se ha implementado las reparaciones como política de Estado.

\section{Las reparaciones y los programas sociales}

En julio del 2005, el Estado peruano promulgó la Ley N. ${ }^{\circ}$ 28592, Ley del Plan Integral de Reparaciones (PIR), norma que reconoce el derecho de las víctimas a ser reparadas por la vulneración de sus derechos humanos durante el periodo de violencia ocurrida entre mayo de 1980 y noviembre del 2000.

16 Latinobarómetro. Informe (2017, pp. 17-18, 26).

17 Según la Encuesta Nacional de Hogares (ENAHO), realizada por el INEI, la tasa de pobreza se elevó un punto porcentual en el 2017, al pasar de $20.7 \%$ a $21.7 \%$ de la población. La zona con mayor deterioro en el país fue Lima, donde la pobreza escaló desde $11 \%$ hasta $13.3 \%$, alcanzando a 180000 personas adicionales. Esto representa la mitad del incremento en el ámbito nacional. El Comercio, 24 de abril del 2018: "Pobreza en el Perú sube por primera vez en el milenio". 
En consecuencia, señala la obligación del Estado peruano en implementar mecanismos de reparación.

Las reparaciones son un conjunto de acciones en favor de las víctimas orientadas al reconocimiento de su condición como tales, y que promueve el acceso a justicia, restitución de sus derechos, resolución de las secuelas derivadas de las violaciones a los derechos humanos y reparación material y moral por los daños sufridos. ${ }^{19}$ A través de las reparaciones, la democracia debería expresar el reconocimiento del Estado a quienes resistieron, combatieron la subversión y fueron afectados gravemente en sus vidas, convirtiendo sus demandas en acciones concretas para enfrentar las consecuencias de la violencia, reconociendo su dignidad como ciudadanos y para restablecer la confianza en el Estado y la sociedad.

Según Beristain (2009, p. 174), las reparaciones deberían constituir el mayor esfuerzo del Estado por remediar el daño sufrido por las víctimas y prevenir nuevas violaciones a los derechos fundamentales en el futuro: "La reparación hace referencia a un problema sin solución, pero a la vez a la necesidad de un compromiso para restituir los derechos de las víctimas y familiares, ayudar a enfrentar las consecuencias de las violaciones, y promover su reintegración social". De esta manera, tendrían como objetivo "ayudar a las víctimas a mejorar su situación, a enfrentar las consecuencias de la violencia, reconociendo su dignidad como personas y sus derechos [...], para restablecer su confianza en la sociedad y las instituciones" (Beristain, 2009, p. 173).

Para De Greiff (2008, pp. 424-431), las reparaciones deberían ofrecer a las víctimas un conjunto de beneficios por los daños ocasionados directamente por la violencia. En esa medida, el Estado debería reconocer que las víctimas son ciudadanos con igualdad de derechos y que, por la violencia sufrida, merecen un tratamiento especial para el restablecimiento de las condiciones de igualdad frente a los demás ciudadanos. En segundo lugar, el Estado debería realizar acciones para recuperar la "confianza" de las víctimas a través de las reparaciones, restableciendo relaciones de igualdad y respeto con las ellas. En tercer lugar, se debería promover una actitud de solidaridad hacia las víctimas a través del esclarecimiento histórico sobre las consecuencias de la violencia para comprometerlas en la construcción de una sociedad más democrática.

19 El Plan Integral de Reparaciones (PIR) consta de siete programas de reparaciones: programa de reparaciones colectivas, simbólicas, educación, restitución de derechos ciudadanos, promoción y facilitación al acceso habitacional y económicas. Artículo $3^{\circ}$ del Decreto Supremo N. ${ }^{\circ} 015-2006-J U S$, que aprobó el reglamento de la Ley $\mathrm{N}^{\circ}{ }^{\circ} 28592$, ley que crea el PIR. 
En el Perú, las reparaciones se han implementado a través de programas sociales, confundiendo los objetivos de la reparación con la necesidad de alivio de la pobreza y vulnerabilidad de las víctimas. Así, para implementar el programa de reparaciones en salud, se ha incluido a las víctimas en el Seguro Integral de Salud (SIS). En el caso de las reparaciones en vivienda, se viene entregando un bono económico a través del programa Techo Propio. En tanto, las reparaciones en educación se centran en la Beca Repared, una beca que forma parte del programa Beca 18. El SIS, Techo Propio y Beca 18 son programas de alivio de la pobreza de carácter temporal y buscan atenuar las necesidades más urgentes de los grupos más pobres.

La Comisión Multisectorial de Alto Nivel (CMAN) es la entidad encargada del diseño, coordinación y seguimiento del cumplimiento del PIR. ${ }^{20} \mathrm{La}$ CMAN se encarga de implementar dos de los siete programas de reparaciones (colectivas y económicas); los otros programas se implementan a través de programas sociales. El presupuesto de la CMAN obedece a la coyuntura política favorable a las reparaciones. En el 2014, el presupuesto superó los 100 millones de soles anuales, de los cuales, el $87.4 \%$ se dirigió a las reparaciones económicas. En el 2015, el presupuesto fue apenas la quinta parte del 2014. En el 2016 se duplicó la cifra del 2015, y en el 2017 se triplicó. En el 2018, el MEF apenas asignó un presupuesto anual de 14 millones 210 mil de soles, la cuarta parte de lo asignado en el 2017. ${ }^{21}$ Con estos vaivenes, ¿qué políticas de reparaciones se pueden sostener en el tiempo?

Este artículo se centra en señalar algunas hipótesis para explicar por qué las reparaciones se vienen implementando a través de programas sociales. Las reparaciones tienen un importante componente simbólico que reconoce el sufrimiento específico ocasionado por la violencia a las víctimas. Este componente fundamental no lo tienen los programas sociales. En esa medida, las reparaciones deberían constituirse en medidas "especiales" o "diferenciadas" para el restablecimiento de condiciones de igualdad de las víctimas frente a los demás ciudadanos y la sociedad en su conjunto. A pesar de los esfuerzos del Estado por hacer excepciones en los programas sociales para incluir a las víctimas, no se reconoce que un programa social permita

20 La CMAN está integrada en representación del Estado por delegados de los ministerios del Interior, Economía y Finanzas, Mujer y Poblaciones Vulnerables, Defensa, Educación, Cultura, Agricultura y Riego, Trabajo y Promoción del Empleo, y en representación de la sociedad civil por la Asociación Nacional de Centros, la Coordinadora Nacional de Derechos Humanos, la Asamblea Nacional de Rectores (reemplazada por la Asociación de Universidades del Perú) y el Consejo de Decanos de los Colegios Profesionales.

21 Fuente: CMAN. 
repararlas. Para la Defensoría del Pueblo (2013, p. 58), "la inclusión de las víctimas en un programa social no puede ser considerada una forma de reparación, pues aquel no respeta los enfoques ni los objetivos y componentes de un programa de reparaciones".

La exministra de Justicia y Derechos Humanos Marisol Pérez Tello es categórica al señalar que los programas sociales no reparan: "El SIS es una falta de respeto, porque tendrían el SIS igual por su situación socioeconómica; entonces, al contrario, cuando les das su certificado, y ellos van con su certificado al SIS y la señora del SIS se mata de risa y les dice: '¿Y esta vaina que es?'. Es realmente ofensivo”. ${ }^{22}$ De esta forma, la atención a través de programas sociales confunde y maltrata a las víctimas, pues, en su gran mayoría, podrían fácilmente acceder a estos programas por su condición de pobreza o pobreza extrema.

\section{Las hipótesis}

Según el Registro Único de Víctimas (RUV), son 179545 mil víctimas reconocidas como beneficiarias del PIR, ${ }^{23}$ de las cuales, la mayoría reside en cuatro regiones del país: Ayacucho (27.2\%), Lima (18.9\%), Huánuco (12.2\%) y Junín (9.5\%).

Del universo de beneficiarios del PIR, solo el 5\% alcanzó algún grado técnico o superior en su formación educativa mientras que el porcentaje de beneficiarios en condición iletrada superó el 18\%. Si analizamos este universo por nivel educativo, el contraste entre Lima y Ayacucho es dramático. En Lima residen el mayor número de beneficiarios que lograron educación técnica y superior (28.6\%), mientras que en Ayacucho residen el mayor número de beneficiarios en condición iletrada (41.9\%). Por otra parte, la mayoría de beneficiarios del PIR superan los cincuenta años de edad (45\%).

¿Cuál ha sido el impacto de las reparaciones en la vida de las víctimas? ¿Por qué los programas de reparaciones de salud, educación y vivienda se vienen implementando a través de programas sociales? En este artículo se

22 Entrevista a la exministra de Justicia y Derechos Humanos, Marisol Pérez Tello.

23 Las cifras usadas en esta investigación fueron proporcionadas por la Oficina de Base de Datos y Programación de la Comisión Multisectorial de Alto Nivel (CMAN), entidad encargada del diseño, coordinación y seguimiento del cumplimiento del PIR. 
ensaya tres hipótesis para explicar qué factores contribuyeron a establecer las reparaciones a través de programas sociales.

En primer lugar, la derrota militar del senderismo ha sido interpretada como un triunfo del Ejército, soslayando el papel de la resistencia campesina para vencer a la subversión. Hacia fines de 1980, las rondas campesinas comenzaron a multiplicarse y resistieron la insania de Sendero Luminoso, lo cual coincidió con la implementación de una nueva estrategia de las Fuerzas Armadas. Sin olvidar que los militares masacraron a los campesinos en los primeros años de la guerra, el discurso hegemónico de la victoria del Ejército sobre Sendero terminó debilitando las reparaciones al situar a las víctimas como parte del "costo social" de acabar con el terrorismo.

La resistencia de las autoridades comunales generó la insania de la violencia subversiva, abriendo la caja de Pandora sobre los reales propósitos de Sendero Luminoso. Miles de campesinos, hombres y mujeres, perdieron la vida para salvar la de sus hijos, tal como lo cuenta Alejandro, en el siguiente testimonio: ${ }^{24}$

Mi papá era gobernador, juez, siempre cambiaba cargo. Como él era licenciado del Ejército, siempre el pueblo lo nombraba porque era un poco disciplinado. Mi padre me sacó a los trece años más o menos. Me dijo: "Tú tienes que salir de acá porque si no cualquier rato te llevan, a mí no me va a pasar nada", me decía mi padre, "yo ya estoy viejo, ustedes salgan de acá". Entonces he ido a Ica, y ahí escuché la noticia que el 31 de diciembre lo asesinaron (Alejandro, 49 años, Huaycán).

Los maestros y líderes sociales también fueron actores de resistencia durante el periodo de violencia. Ellos fueron víctimas de la represión de los senderistas y de las fuerzas del orden. Los senderistas los acusaban de "soplones" y los militares, de "terroristas". En este contexto, Gustavo recuerda a su padre, un maestro y líder sindical, como un hombre dedicado a la "defensa de los pueblos", que fue desaparecido por los militares mientras luchaba por sus ideales en Cerro de Pasco:

Él era de carrera profesor y aparte se dedicaba al sindicato de mineros y también al Frente de Defensa de todos los pueblos de Cerro de Pasco. Se dedicó a eso y, a la vez, como era profesor, siempre estuvo en el SUTEP. Por el motivo de eso,

24 Los testimonios que se usarán en este artículo forman parte de las entrevistas realizadas para la elaboración de mi tesis para optar por el grado de magíster en la Facultad de Ciencias Sociales de la Universidad Nacional Mayor de San Marcos, en noviembre del 2018. 
llegan a pensar los militares que mi padre tenía otros fines y por esa razón lo inculparon a mi padre de terrorista y luego lo desaparecieron (Gustavo, 42 años, San Juan de Lurigancho).

En segundo lugar, luego de la transición democrática del año 2000, se siguió gobernando con las mismas estructuras económicas y sociales heredadas del régimen fujimorista. Ello ha generado que se viva una especie de frustración democrática, donde la mayoría de los derechos ciudadanos son reconocidos, pero en condiciones sociales limitadas para ejercer sus derechos. Para Edgar, presidente de la Asociación Reflexión de Inocentes Liberados, hoy se sigue gobernando sobre las mismas estructuras del régimen dictatorial,

Hay una derrota militar, obviamente. Por métodos democráticos no se venció al terrorismo. Los que siguieron gobernando después del noventa siguieron siempre siendo los mismos, no se desmontó toda la mafia (Edgar, 50 años, San Juan de Lurigancho).

Consecuencia de ello, el Estado no ha logrado recuperar su rol hegemónico en la vida social, mientras el mercado sigue teniendo un poder determinante en sus decisiones, aliviando las demandas ciudadanas a través de programas sociales. Las reparaciones han seguido ese mismo camino. Pero las reparaciones no deberían ser programas de alivio a la pobreza, sino un conjunto de acciones donde el Estado exprese su reconocimiento a quienes resistieron y se enfrentaron a la subversión, y a quienes resultaron afectados en el desarrollo de sus vidas. Al respecto, Proceso, un socio de la Asociación Reflexión de Inocentes Liberados, comenta que la atención en el SIS gratuito, que se le otorgó como reparación en salud, es deficiente y que no hay un buen trato hacia los usuarios.

En el trato del SIS para cualquiera, sea víctima o no víctima, es como decir cumplir con esa gente. No es como que realmente quieren hacer algo bueno para ellos. Ya las enfermeras así por cumplir, como decir para que no molesten. Es así (Proceso, 56 años, San Juan de Lurigancho).

Teófila nos cuenta una situación de maltrato y discriminación que sufrió por parte de unas enfermeras que la atendieron en la posta Manylsa, ubicada en el distrito de Ate. Señala que cuando dijo que las víctimas son "especiales", se rieron. Contó que cuando las víctimas hablan en quechua, se burlan y dicen no 
"entenderlas". Estas situaciones solo generan más desconfianza en el Estado y las reparaciones.

Cuando decimos que somos víctimas, cuando decimos que somos especiales. "Qué especiales”, nos dicen. "¿Qué cosa tienes tú? ¿Estás manco, cojo, se ha roto los huesos?", así te dicen. Ellos no saben. De repente aquí en Manylsa no les vienen a llamar la atención. Algunos son quechuahablantes. "Yo no te entiendo", te dicen. Entonces, tú cómo puedes ir a una posta si te están dando maltrato (Teófila, 50 años, Ate-Vitarte).

Floriano, exalcalde de Accomarca en los años de la violencia y desplazado residente en Ate-Vitarte desde 1989, señala que el SIS gratuito es una forma de "apoyo social" que ha recibido del Estado en su condición de "pobre", y no reconoce a este seguro como parte de las reparaciones:

Ese programa social que nosotros hemos recibido del Estado, y no ha sido directo de las víctimas. Si yo he recibido apoyo social, sí, pero por la extrema pobreza. Eso no considero reparación en salud, debe ser por lo menos como un seguro, o debe ser como una pensión; eso se llama reparación. Es que no hay reparación. Yo considero que por lo menos deben dar una pequeña pensión a todos los afectados, eso sería algo que podemos recibir de parte del Estado (Floriano, 66 años, Ate-Vitarte).

Las víctimas necesitan percibir un trato "diferenciado" en las acciones que realiza el Estado en su favor para comprender que son "reparaciones". En ausencia de un Estado que repare, la sensación de injusticia aumenta y las "revictimiza". Como lo comenta Jorge, quien perdió a sus padres en Ocros (Huamanga), se necesita que el Estado reconozca y genere oportunidades de desarrollo para las víctimas. Él dice que no pudo estudiar porque la violencia le "afectó la memoria". Cuenta que iba al colegio y no aprendía, pues siempre pensaba en sus padres. Jorge vive hoy en Huaycán, y siente que tiene pocas oportunidades laborales por su falta de preparación educativa.

En Ocros fallecieron mis padres. Primero lo mataron a mi padre, luego a mi madre por defenderle. Yo también quise defender, y tuve que escaparme dentro del maizal. Me escapé descalzo en medio de la lluvia. Yo pensaba que era como un sueño [...]. No es justo tantas cosas que hemos pasado. Nuestros padres han sido personas trabajadoras, que han trabajado por el pueblo; nadie ha reconocido eso. Yo prácticamente me tenía que amanecer trabajando. Estamos cada día peor. Ahora hay menos oportunidades que antes. Antes había más trabajo, ahora no. Ahora hay mucha competencia por todos lados. (Jorge, 45 años, Huaycán). 
Por último, se necesita reconocer a las víctimas como actores importantes en la pacificación del país. El campesinado sufrió el desprecio y la violencia del Estado y de Sendero, pero aun así combatieron por darles paz a sus pueblos y al país. En la historia oficial, se observan a las víctimas como "pobres víctimas", marginadas y excluidas, pero no siempre como actores de resistencia.

$\mathrm{Al}$ respecto, Edgar nos comenta que al ser las víctimas serranas y quechuahablantes las autoridades no se preocuparon por el impacto generado por la subversión en sus pueblos. De esta manera, el disimulado racismo y las actitudes de desprecio subsistentes en la sociedad peruana continúan afectando a las víctimas, mellando su reconocimiento y la implementación de las reparaciones.

La mayoría de víctimas de la violencia son quechuahablantes, son los cholos, los serranos, los sin nombre, los que no son ciudadanos. Como dice Alan García: "De segunda categoría". Entones no van a perder el tiempo en esos cojudos [...]. Y aquí, mientras la guerra estaba en Ayacucho, acá la gente estaba feliz de la vida, hasta que hubo el tema de Tarata recién entendieron la magnitud de la guerra. Entonces hay un problema de racismo, no vamos a reparar a cholos, pues (Edgar Rivadeneyra, 50 años, San Juan de Lurigancho).

La falta de reconocimiento a las víctimas ha generado situaciones extremas donde los campesinos, víctimas y afectados, son tildados de "terroristas". A pesar de los años transcurridos, las víctimas se sienten marginadas en una ciudad que nunca los incluyó del todo. Delfina cuenta que llegó al distrito de Ate-Vitarte desplazada desde Huamanga, en 1984. Ella cuenta que antes vivía "la felicidad", pues tenía su casa, ganado todo para poder vivir. En cambio, aquí en la capital, se ha sentido discriminada:

Sí, me he sentido discriminada. En mi zona nos marginaban. Nos decían: "Usted ayacuchana, serrana, terrorista". Nos trataban así. En vez de acogernos, nos trataban mal. Cuando íbamos a buscar trabajo, no nos daban, siempre nos marginaban (Delfina Raucana, 49 años, Ate-Vitarte).

Como señala Delfina, y también Floriano, la mayor dificultad ha sido conseguir trabajo en la ciudad y sobrevivir:

Porque eres ayacuchano dicen: "Ah, no, son terrucos". Por motivo de eso no hemos tenido trabajo, y mucha gente que no tiene trabajo, y hoy día estamos tercera edad y no tenemos nada. Pero no había trabajo, la única salida era la construcción, cachuelos (Floriano Quispe, 66 años, Ate-Vitarte). 
Por eso, cuando los gobernantes hablan de "reconciliación", las víctimas piensan en su reconocimiento y el respeto de sus derechos. Ello solo sería posible, en palabras de Teófila, cuando el Gobierno sea transparente, cumpla y repare; es decir, cuando "el Gobierno haga bien al pueblo":

Si ellos realmente quieren reconciliarse, no estaríamos pidiendo, dando esas miserias, pensando que con el SIS nos van a hacer callar. Nada de eso. A nuestros derechos ellos no están respetando. Cómo vamos a reconciliarnos en la situación en la que estamos. Qué confianza vamos a tener con estas autoridades. Reconciliación cuando haya un Gobierno transparente, cuando haya un Gobierno que haga bien al pueblo (Teófila, 45 años, Ate-Vitarte). 


\section{Bibliografía}

Adrianzén, A. (2009). La transición inconclusa. De la década autoritaria al nacimiento del pueblo. Lima: Otra Mirada.

Asamblea General de las Naciones Unidas (1948). Declaración Universal de Derechos Humanos. Nueva York: ONU.

Beristain, C. (2009). Diálogos sobre la reparación. Qué reparar en los casos de violaciones de derechos humanos. San José: Instituto Interamericano de Derechos Humanos.

Burt, J.-M. (2011). Violencia y autoritarismo en el Perú. Bajo la sombra de Sendero y la dictadura de Fujimori. Lima: IEP, EPAF, SER.

Comisión de la Verdad y Reconciliación (2003). Conclusiones. Informe final. Lima: CVR.

Comisión de la Verdad y Reconciliación (2003). Capítulo 1, III parte: Las secuelas psicosociales. Informe final. Lima: CVR.

Defensoría del Pueblo (2009). A diez años de verdad, justicia y reparación. Avances, retrocesos y desafios de un proceso inconcluso. Informe defensorial, 162. Lima.

Degregori, C. I. (2010). Qué difícil es ser Dios. El Partido Comunista del Perú-Sendero Luminoso y el conflicto armado interno en el Perú: 1980-1999. Lima: IEP.

Degregori, C. I. (1996). Cosechando tempestades: las rondas campesinas y la derrota de Sendero Luminoso. En C. I. Degregori, J. Coronel, P. del Pino y O. Starn. Las rondas campesinas y la derrota de Sendero Luminoso. Lima: IEP, Universidad Nacional de San Cristóbal de Huamanga.

Degregori, C. I., Rivera Paz, C. (1993). Perú 1980-1993: Fuerzas Armadas, subversión y democracia. Redefinición del papel militar en un contexto de violencia subversiva y colapso del régimen democrático. Documento de trabajo, 53. Serie Documentos de Política, 5. Lima: IEP.

De Greiff, P. (2006). Justice and Reparations. En P. de Greiff (Ed.). Handbook of Reparations. Nueva York: Oxford University Press.

De Tocqueville, A. (1957). La democracia en América. México D. F.: Fondo de Cultura Económica.

Ejército del Perú (2010). En honor a la verdad: versión del Ejército sobre su participación en la defensa del sistema democrático contra las organizaciones terroristas. Lima: Gráfica Cánepa.

Flores Galindo, A. (1999). La tradición autoritaria: violencia y democracia en el Perú. Lima: SUR. Casa de Estudios del Socialismo, APRODEH.

Gonzales, E. (1990). Una economía bajo la violencia. Perú, 1980-1990. Documento de trabajo, 40, Serie Economía, 14. Lima: IEP. 
Gonzales, R. (1993). Ayacucho: la espera del gaucho. Entrevista al general Luis Cisneros Vizquerra. Quehacer, 20.

López, S. (2010). Estado y ciudadanía en el Perú. En El Estado en debate: múltiples miradas. Nueva York: Programa de las Naciones Unidas para el Desarrollo.

López, S. (1997). Ciudadanos reales e imaginarios. Concepciones, desarrollo y mapas de ciudadanía en el Perú. Lima: Instituto de Diálogo y Propuestas.

Lynch, N. (1992). La transición conservadora. Movimiento social y democracia en el Perú (1975-1978). Lima: Zorro de Abajo Ediciones.

Lynch, N. (2009). El argumento democrático sobre América Latina. La excepcionalidad peruana en perspectiva comparada. Lima: Fondo Editorial de la Facultad de Ciencias Sociales de la Universidad Nacional Mayor de San Marcos.

Lynch, N. (2014). Cholificación, república y democracia. El destino negado del Perú. Lima: Otra Mirada.

Macher, S. (2014). ¿Hemos avanzado? A 10 años de las recomendaciones de la Comisión de la Verdad y Reconciliación. Serie: Estudios sobre Memoria y Violencia, 6. Lima: IEP.

Mendoza, A. (2016). Perú: brechas latentes. Índice de avance contra la desigualdad. Lima: Oxfam.

Nun, J. (2002). Democracia: ¿gobierno del pueblo o gobierno de los políticos? Buenos Aires: Siglo XXI Editores.

Tanaka, M. (2013). Las ambigüedades del IF de la CVR en la explicación de las causas y dinámica del conflicto armado interno. Argumentos, 7(4). Tomado de: https://revistaargumentos.iep.org.pe/wp-content/uploads/2014/04/tanaka_set13.pdf.

Tapia, C. (2018). Tiempos oscuros (1983-1995). Lima: Otra Mirada.

Tapia, C. (1997). Las Fuerzas Armadas y Sendero Luminoso. Dos estrategias y un final. Lima: IEP.

Tilly, C. (2004). ¿De dónde vienen los derechos? Sociológica, 19(55), pp. 273-300.

Uprimny, R., y Saffon, M. P. (2009). Reparaciones transformadoras, justicia distributiva y profundización democrática. En C. Díaz, N. Sánchez y R. Uprimny (Eds.). Reparar en Colombia: los dilemas en contextos de conflicto, pobreza y exclusión (pp. 31-70). Bogotá: DeJusticia. 